ISSN: 0213-2079 - ISSN electrónico: 2386-3889

DOI: https://doi.org/10.14201/shhmo2017391301325

\title{
DIPLOMACIA, SERVICIO CORTESANO Y TINTAS CATÓLICAS: LA QUERELLA LONDINENSE DE FRANCISCO DE MELO MANUEL"
}

\section{Diplomacy, Courtly Service and Catholic Inks: The London Lawsuit of Francisco de Melo Manuel}

Cristina BRAVO LOZANO

Universidad Pablo de Olavide, Sevilla

Correo-e: cbraloz@upo.es

RESUMEN. En 1676 Francisco de Melo Manuel, embajador portugués en Londres y lord chamberlain de la reina Catalina de Braganza, se vio envuelto en una controversia tipográfica que afectaría a su dignidad diplomática y a su oficio palatino. El servicio y obediencia a dos miembros de la casa real lusa, con distinta naturaleza y atribuciones, muestra el delicado equilibrio entre la esfera de negociación política y el ámbito doméstico. Teniendo en consideración su trayectoria y doble condición, la licencia de impresión de un libro católico en la corte protestante derivó en una querella que, si bien puede interpretarse como un caso eventual, pone de relieve la realidad confesional imperante en la Inglaterra restaurada. Asimismo, se infiere cómo tales impresos encontraron en la diplomacia y el entorno de la consorte regia canales informales de difusión y circulación.

Palabras clave: diplomacia; Casa Real; tipografía; catolicismo; Francisco de Melo Manuel; Catalina de Braganza; Carlos II Estuardo; Portugal; Inglaterra.

* Este trabajo se ha realizado al amparo del programa Juan de la Cierva-Formación (FJCI2014-21225) y se incluye en el marco de los proyectos de la Dirección General de Investigación del Ministerio de Economía y Competitividad El modelo policéntrico de soberanía compartida (siglos XVI-XVIII): una vía alternativa a la construcción del Estado moderno (HAR2013-45357-P) y Sociedad cortesana y redes diplomáticas: la proyección europea de la monarquía de España (1659-1725) (HAR2015-67069-P MINECO/FEDER).

(C) Ediciones Universidad de Salamanca / ®@ Stud. his., H. ${ }^{a}$ mod., 39, n. 1 (2017), pp. 301-325 
ABSTRACT: In 1676 Francisco de Melo, Portuguese ambassador in London and lord chamberlain of the Queen Catherine of Braganza, was involved in a typographic controversy that affected his diplomatic dignity and his palatine office. Service and obedience to two members of the Lusitanian Royal House, with different natures and responsibilities, show the delicate balance between the political sphere of negotiation and the domestic space. According to his career and his dual position, the impression's permission of a catholic book in the protestant court caused the dispute analyzed in these pages. Although it can be interpreted as an eventual case, it emphasizes the confessional reality of England and how such printed texts found ways of diffusion through the diplomacy and the environment of the royal consort.

Key words: diplomacy; Royal House; Typography; Francisco de Melo Manuel; Catherine of Braganza; Charles II Stuart; Portugal; England.

En 1686, pocas semanas después de haber sido coronado rey de Inglaterra, Jacobo II definió las líneas maestras que articularían su reinado en materia religiosa. La política de incentivación y propagación del catolicismo, como él mismo confesaba, encontró en las tintas y los tipos de la imprenta un instrumento de gran utilidad para la exaltación de la autoridad regia y la difusión de los principios romanos en sus reinos, como a la inversa había sucedido un siglo atrás con los fundamentos anglicanos ${ }^{1}$. Fueron dos pliegos manuscritos, «que a los principios anduvieron tan secretos y que se hallaron en uno de los escritorios del último rey», es decir, Carlos II, los que trazaron un programa de divulgación basado en la idea de la imitatio que despertaría en el pueblo la lectura de sendas cartas o el conocimiento del contenido de la misma. Acompañadas de otro papel con las razones que motivaron la conversión de su primera esposa, Ana Hyde, el rey Jacobo mandó traducir y dio a la imprenta las epístolas del finado monarca en que declaraba su convicción católica, religión a la que se convirtió en el lecho de muerte ${ }^{2}$. Como explicó el nuncio Ferdinando d'Adda en su frecuente correspondencia con el cardenal Alderano Cybo, secretario de Estado pontificio, el nuevo

1. Pincus, S.: 1688, la primera revolución moderna. Barcelona, 2013, pp. 231-232.

2. El nuncio, Ferdinando d'Adda, envió a Roma una copia de las cartas en italiano. Archivio Segreto Vaticano [en adelante, ASV], Segreteria di Stato. Inghilterra, 10, fols 34r-38v. El legado modenés en la corte de Londres, Giacomo Ronchi, también tradujo sendos impresos a esta lengua para remitírselos al duque. Archivio di Stato di Modena [en adelante, ASMo], Ambasciatori, Inghilterra, busta 4. Carta de Giacomo Ronchi al duque de Módena. Londres, 4 de marzo de 1686.

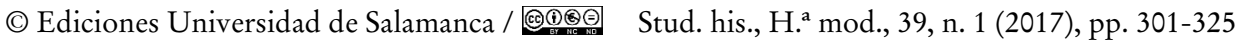


soberano inglés esperaba que otros siguieran el ejemplo de su hermano, recalando misioneros para tal fin ${ }^{3}$.

El impacto que generó la noticia y la repercusión de tan relevantes declaraciones autógrafas no se correspondió con el acceso al texto impreso. En una carta enviada por Felipe de la Guerra, cónsul español en Londres, al duque del Infantado se señalaron las causas por las cuales «no ha querido el rey que se impriman sino unos tantos ejemplares». Dejando la distribución a la liberalidad de su mano, Jacobo II evitaba que no fuesen tenidos por auténticos, pues el obispo anglicano de la ciudad, Henry Compton, se había adelantado a cuestionar la existencia de tales testimonios originales. El prelado llegó a afirmar que se trataba de una imposición y «que una cosa tan mala no podía venir ni ser escrita de un rey tan grande y $\tan$ bueno» como lo había sido el difunto Carlos $\mathrm{II}^{4}$.

Merced al asenso regio y su implementación interesada como instrumento político para mediatizar a las masas, las prensas católicas experimentaron un progresivo auge durante el reinado jacobita. Todo ello se diferenciaba del período precedente, cuando la introducción de Popish books en el archipiélago británico, su circulación y estampa habían sido tipificados como crimen lege. El código normativo regulador de dicha cuestión procuró prevenir cualquier conato romano inherente en las obras de naturaleza papista o la difusión del mensaje contenido en sus páginas. Según la lógica imperante en Inglaterra, su influencia y capacidad de persuasión en las mentalidades de aquellos que consumiesen este tipo de lecturas atentaba contra la religión oficial del reino, la anglicana. Una querella tipográfica que se dio en la corte londinense menos de un decenio atrás, en el verano de 1676, con Francisco de Melo Manuel, embajador portugués y lord chamberlain de la reina Catalina de Braganza, como protagonista principal evidencia el impacto político y la incidencia social de la palabra escrita católica en la realidad de la Restauración inglesa.

1. Negociados políticos y oficios domésticos: Francisco de Melo Manuel AL SERVICIO DE LOS BRAGANZA

Las relaciones de la monarquía inglesa con el monarca portugués Alfonso VI se habían visto impulsadas con fuerza en 1661 tras el matrimonio de Carlos II

3. ASV, Segreteria di Stato. Inghilterra, 11. Carta de Ferdinando d'Adda al cardenal Alderano Cybo. Londres, 21 de enero de 1686.

4. Archivo Histórico de la Nobleza [en adelante, AHNOB], Osuna, CT. 62, D. 55. Carta de Felipe de la Guerra al duque del Infantado. Londres, 4 de febrero de 1686.

(C) Ediciones Universidad de Salamanca / ®@ Stud. his., H. ${ }^{a}$ mod., 39, n. 1 (2017), pp. 301-325 
con la infanta Catalina de Braganza y la firma de un tratado de alianza mutua ${ }^{5}$. Un año después, la nueva reina hacía su entrada en Londres acompañada por un amplio séquito de nobles, damas y religiosos lusitanos ${ }^{6}$. Entre ellos se encontraba Francisco de Melo Manuel (Fig. 1). Este hombre de letras, avezado en materia política, nació en 1626, en el seno de una familia fidalga vinculada con el gobierno de la ciudad de Lamego. Su padre, Gomes de Melo, ocupó el puesto de alcaide mayor de su fortaleza y era caballero de la insigne Ordem de Cristo y señor del morgado de Ribeirinha (isla de San Miguel) y de Zambujalinho (Évora); mientras su madre, Marinha Drago de Portugal, era hija de Nuno Cardoso, capitán de la misma y señor del morgado de Tapia, de los Reguengos de Folhadal y Paramos ${ }^{7}$. Instruido en poesía, como su conocido primo Francisco Manuel, la calidad de sus ingenios y composiciones en verso fueron aplaudidas por las elites intelectuales de su tiempo, ingresando en la afamada Academia dos Generosos, que llegaría a presidir en varias ocasiones ${ }^{8}$. Además de sus dotes literarias, cultivó las lenguas y se educó en las sagradas escrituras y la historia, con particular dedicación a los estudios genealógicos. En 1645, tras la muerte de su progenitor, heredó la alcaidía mayor de Lamego y el título de comendador de São Pedro da Veiga de Lila, en la Ordem de Cristo, en la que se había cruzado9. Treinta años después, también

5. El matrimonio y las implicaciones políticas, económicas y religiosas del mismo han sido analizadas en Grose, C. L.: «The Anglo-Portuguese Marriage of 1662», Hispanic American Historical Review, X, 1930, pp. 320-325; Belcher, G. L.: «Spain and the Anglo-Portuguese Alliance of 1661», Journal of British Studies, 15, 1975, pp. 67-88; VAlladares, R.: La rebelión de Portugal, 1640-1680. Guerra, conflicto y poderes en la monarquía hispánica. Valladolid, 1998, pp. 171-180; y MadwaY, L.: «Rites of Deliverance and Disenchantment: The Marriage Celebrations for Charles II and Catherine of Braganza, 1661-1662», The Seventeenth Century, XXVII: 1, 2012, pp. 79-103.

6. La composición del séquito que acompañó a Catalina de Braganza, los pormenores del viaje hasta Londres y su llegada a Portsmouth, donde se celebrarían los esponsales regios, se exponen en RaU, V.: «D. Catarina de Bragança - Raínha de Inglaterra», O Instituto. Revista científica e literaria, 98, 1941, pp. 69-80: 69-72. En su Diarie, Samuel Pepys también incluye algunas menciones acerca de la acogida y demostraciones ante la llegada de la reina y su entrada pública en Londres, el 23 de agosto de 1662. Pepys, S.: Diarios. Sevilla, 2014, pp. 131-140.

7. Leal de Faria, A.: Arquitectos da. A diplomacia portuguesa, 1640-1815. Lisboa, 2008, p. 247.

8. Prestage, E.: D. Francisco Manuel de Mello. Esboço Biographico. Coimbra, 1914, pp. 302 y 304 .

9. Arquivo Nacional Torre do Tombo [en adelante, ANTT], Registro Geral de Mercês, Doações da Torre do Tombo, L. 4, f. 158. Carta de la Alcaidaria mayor de la ciudad de Lamego. S. 1., 19 de julio de 1645; y ANTT, Registo Geral de Mercês, Ordens Militares, L. 2, fol. 102. Alvará de la encomienda de São Pedro da Veiga de Lila para Francisco de Melo Manuel por la muerte de su padre, Gomes de Melo. S. l., 4 de septiembre de 1645.

(C) Ediciones Universidad de Salamanca / ®@ Stud. his., H. ${ }^{a}$ mod., 39, n. 1 (2017), pp. 301-325 
fungiría las encomiendas de São Miguel de Linhares y Santa Maria de Torredeita ${ }^{10}$. Durante la rebelión portuguesa contra la monarquía de España, Melo desempeñó distintos cargos palatinos para la Casa de Braganza, con la que, además, le unían lazos de parentesco desde el siglo $\mathrm{xv}^{11}$. No solo fue trinchante mayor del infante dom Pedro, sino también ejerció como su consejero. Sus prendas, prudencia de juicio y acreditados valores cortesanos, así como sus servicios continuados a los regentes le fueron reconocidos con el envío a Inglaterra, asistiendo a la nueva reina en calidad de camarero mayor, junto con su hermana María de Portugal, dama de la soberana Luisa de Guzmán y condesa de Penalva ${ }^{12}$.

Durante su estancia londinense, el protagonismo político de dom Francisco fue en aumento, al igual que la confianza de doña Catalina. Con la marcha confidencial de Francisco de Melo e Torres, marqués de Sande, a Francia para negociar el matrimonio de Alfonso VI en 1663, le sustituyó al frente de la embajada portuguesa y en la gestión del archivo diplomático. En esta labor estuvo asistido por el capellán mayor del oratorio regio, el obispo Richard Russell. Entre otros asuntos, como ha puesto de manifiesto Ana Leal de Faria, tuvo que negociar el proceso de entrega de la factoría de Bombay a Inglaterra, contemplada como parte de la dote de la reina ${ }^{13}$. Se trataba de una cuestión problemática, determinada por las connotaciones económicas relativas al control del enclave, los intereses mercantiles británicos en su área de influencia y los intentos fallidos del legado por revertir la cesión a cambio de una indemnización dineraria. Pese a sus esfuerzos, Melo no consiguió su objetivo, pues la entrega efectiva se produjo dos años después ${ }^{14}$.

La comprometida gestión del negociado y la férrea defensa de los intereses ultramarinos lusos le convertían en el ministro más a propósito para otro encargo diplomático: el reajuste del tratado de La Haya de 1661 establecido con las Provincias Unidas para concluir el conflicto heredado desde tiempo de los Felipes ${ }^{15}$. En 1667 el regente Pedro de Braganza le nombró por su embajador

10. ANTT, Registo Geral de Mercês, Ordens Militares, L. 8, f. 375r y L. 10, fols 65r y 66v. Alvarás de la encomienda de São Miguel de Linhares y Santa Maria de Torredeita a Francisco de Melo Manuel. S. 1., 15 de enero y 21 agosto de 1675.

11. Varela Flor, S.: «D. Francisco de Melo Manuel da Câmara (1626-1678): biografia, património, estatuto social e fidelidades», Análise Social, 215:1-2, 2015, pp. 358-359.

12. Barbosa Machado, D.: Bibliotheca Lusitana. Lisboa, 1747, tom. II, pp. 200-201.

13. Leal de Faria: Arquitectos da paz..., op. cit., pp. 128 y 220.

14. Khan, S. A.: «The Anglo-Portuguese negotiations relating to Bombay, 1660-1677», Journal of Indian History, 1/3, 1922, pp, 419-570; y HumberT, J.: «Bombay, dote de la princesa Da Catalina de Braganza, 1661-1670», Boletín de la Asociación Española de Orientalistas, 4, 1968, pp. 99-117.

15. Santos Pérez, J. M. y Cabral de Souza, G. F. (eds.): El desafío holandés al dominio ibérico en Brasil en el siglo XVII. Salamanca, 2006.

(C) Ediciones Universidad de Salamanca / ®@ Stud. his., H. ${ }^{a}$ mod., 39, n. 1 (2017), pp. 301-325 
extraordinario ante los Estados Generales. Además de encargarse de consolidar los aspectos mercantiles que quedaron pendientes en el convenio precedente, la misión de Melo se centraría en reclamar la devolución de las plazas de Cochim y Cananor, en manos holandesas desde 1663. A lo largo de las conversaciones, el representante bragancista hubo de recurrir a la experimentada ayuda del sefardí Jeronimo Nunes da Costa, esgrimiendo el argumento jurídico de la ocupación ilegal ${ }^{16}$. Una vez fue dotado por Lisboa con nuevas instrucciones para plantear los términos del renovado documento, Melo trató de minimizar la débil posición lusa, que implicaría algún tipo de sensible pérdida, bien territorial, bien mercantil ${ }^{17}$. Contando con la garantía de Luis XIV -apoyo agradecido por el propio dom Francisco en un viaje dirigido, ex professo, a París- las complicadas conferencias se resolvieron en 1669 con el pagamento de una elevada cantidad dineraria anual sobre los derechos de la sal de Setúbal durante veinte años, aun con las objeciones puestas por parte neerlandesa ${ }^{18}$.

Sin tiempo para reponerse de tan arduo comisionado, hubo de emprender viaje secreto a Dover y la corte londinense en la primavera siguiente. En esta ocasión, tenía que informarse acerca de la veracidad de ciertos rumores que advertían el posible divorcio real, así como del objeto de la visita de la duquesa de Orleáns a su hermano, el rey Carlos, si bien pronto se supo que constituyeron los contactos previos para una alianza militar anglo-francesa, como se confirmó en febrero de 1672 con el Tratado de Madame. Atento a lo cual, en noviembre de 1670 abandonó definitivamente La Haya para regresar a Inglaterra como legado del regente lusitano. Esta circulación de ministros entre las cortes y repúblicas septentrionales obedece a un fenómeno de interconexión de negociados que se asemeja, en gran

16. Acerca de la trayectoria de este judío portugués, vid. Israel, J. I.: Conflicts of Empires. Spain, the Low Contries and the Struggle for world supremacy, 1585-1713. Londres, 1997, pp. 171-195.

17. Durante tan breve estancia en la corte lisboeta, fue nombrado por el regente Pedro de Braganza señor de Silvã de Cima. Varela Flor, op. cit., p. 362.

18. Leal de Faria, A.: «Missões Secretas e Negociação. D. Francisco Manoel de Mello e D. Francisco de Mello Manoel ao serviço da Coroa Portuguesa», en Pimentel, M. R. y Monteiro, M. R. (eds.): D. Francisco Manuel de Melo. O Mundo é Comédia. Lisboa, 2011, pp. 211-234. El «Tratado de paz, alliança e commercio entre o Principe Regente o Senhor D. Pedro e os Estados Geraes das Provincias Unidas dos Paizes Baixos assignado na Haya em 30 de Julho de 1669; ratificado por parte de Portugal em 10 de Outubro, e pela dos Estados Gerais em 13 de Dezembro do dito anno» se encuentra recogido en Borges De CASTRO, J. F. (coord.): Collecção dos tratados... Lisboa, 1856, tom. I, pp. 444-471. Sobre la cuestión de la sal, vid. RAu, V.: Estudos sobre a História do Sal Português. Lisboa, 1984; y Herrero Sánchez, M.: «La explotación de las salinas de Punta de Araya. Un factor de conflicto en el proceso de acercamiento hispano-neerlandés (1648-1677)», Cuadernos de Historia Moderna, 14, 1993, pp. 173-196.

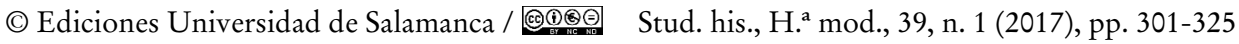


medida, a la praxis política y diplomática desarrollada por la monarquía de España en el ámbito geoestratégico del mar del Norte ${ }^{19}$.

La recepción formal se fue dilatando en el tiempo, tensando las relaciones entre ambas coronas por cuestiones de ceremonial. Pese a los esfuerzos mediadores de Luis XIV para facilitar la audiencia del portugués y las peticiones reiteradas de la consorte en su favor, desde Lisboa se decidió retirar a Melo hacia Francia hasta que se autorizase su entrada con los honores propios al grado que portaba ${ }^{20}$. Esta no se produjo hasta diciembre de 1671, con el consiguiente menoscabo para la representación de dom Francisco. Por decisión regia, y puede que para compensar la larga espera y los perjuicios ocasionados en su misión, se le instaló en el convento de Saint James que, hasta entonces, habían habitado los religiosos franciscanos ${ }^{21}$.

Tal resolución coincidió con el pragmático traslado de la capilla de la reina Catalina a Somerset House para restablecer el otrora altar de su predecesora, Enriqueta María, y favorecer a los católicos con un lugar de culto más céntrico en el entramado urbano londinense ${ }^{22}$. Como informase el conde de Molina, la portuguesa también optó por mudar su lugar de culto personal «para poder quedarse a comer en el palacio los días que habiendo ido a la misa, vuelve a vísperas y para ir a dormir en las ocasiones que el rey suele salir de la villa». No obstante, la decisión se insertó en el debate sobre la viabilidad del divorcio regio ante las dificultades para engendrar un heredero. Así, «los cortesanos y, principalmente los que desean la separación, dicen ser principio para disponerla y, que habiéndole propuesto el rey que escogiese alguna de las casas que tiene en la campaña, ha elegido ella misma» permanecer en la ciudad, en Somerset House ${ }^{23}$.

19. Este fue el caso de Baltasar de Fuenmayor, marqués de Castelmoncayo, que pasó de la embajada de Dinamarca a las Provincias Unidas; o Manuel Coloma, marqués de Canales, quien se hizo cargo de los asuntos diplomáticos en Inglaterra tras su misión diplomática en La Haya.

20. Vieira, A.: Obras escolbidas. Prefacios e notas de António Sérgio e Hernâni Cidade. Lisboa, 1951, vol. II, p. 55.

21. Sobre la capilla de la embajada portuguesa en Londres, vid. WeALE, J. C. M. (ed.): Registers of the catholic chapels Royal and of the Portuguese Embassy chapel, 1662-1829. Londres, 1941, vol. 38.

22. Archivio Storico di Propaganda Fide [en adelante, ASPF], Scritture referiti nei Congresi. Anglia, 1, f. 637v. Relación de la estancia del internuncio en Bruselas, Carlo Francesco Ajroldi, en Londres. Bruselas, 29 de noviembre de 1670.

23. Archivo General de Simancas [en adelante, AGS], Estado, leg. 2545. Carta del conde de Molina. Londres, 18 de mayo de 1671. A partir de 1685, con la entronización de Maria d'Este como reina consorte, el palacio de Somerset House se convirtió en su residencia definitiva. Thurley, S.: «The Stuart Kings, Oliver Cromwell and the Chapel Royal 1618-1685», Architectural History, 45, 2002, pp. 238-274.

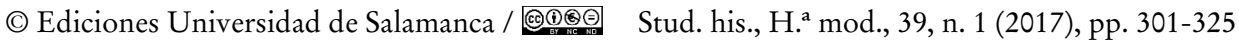


La disponibilidad de este espacio para el ejercicio católico, dentro del área del palacio real de Saint James, se incluía en el marco de las capitulaciones firmadas por el monarca para contraer matrimonio con su consorte lusa, concretamente en el artículo séptimo. El enlace había tenido desde su comienzo marcadas significaciones políticas. Por un lado, provocó serias fricciones en las relaciones anglo-españolas, pues se trataba de una alianza entre Carlos II, el otrora pensionado de Felipe IV, y el tirano portugués Alfonso VI. En Roma se temían las consecuencias de la unión de una infanta católica con un príncipe protestante; y, por último, distintos súbditos británicos mostraron cierta aversión al mismo, ya que el casamiento fue una de las primeras señales de respeto del monarca restaurado hacia la confesión de su esposa ${ }^{24}$. En un clima de revalorización de la religión como factor político, el Estuardo había mostrado en repetidas ocasiones su intención de equiparar a los vasallos católicos con el resto de sectas cuando ciñese la corona. Por esta vía, reconocería su lealtad al partido realista durante la Commonwealth y aplicaba lo declarado en la ciudad neerlandesa de Breda ${ }^{25}$.

Con la llegada de la reina Catalina a Londres en 1662, el catolicismo encontró en la portuguesa un sólido baluarte y se sirvió de su persona y profundo celo religioso como ejemplo. La anuencia para el ejercicio y demostración pública de sus devociones convirtió a la Queen's Chapel, recompuesta tras el desmantelamiento sufrido durante la república, en uno de los lugares sacros más populares de la corte $^{26}$. La singularidad de sus oficios y el equilibrio en su nómina de capellanes

24. En una carta, el barón de Watteville, embajador español en Londres, señaló a Felipe IV cómo los ingleses «tan solamente se templa alguna parte de ellos con esperanza que la dote se ha de reducir a dinero", dadas las estrecheces pecuniarias que atravesaban las arcas reales. Real Academia de la Historia [en adelante, RAH], Salazar y Castro, 9/635, f. 197v. Carta del barón de Watteville a Felipe IV. Londres, 15 de septiembre de 1661. Por su parte, el cardenal Odescalchi advertía que la repercusión política del matrimonio «per le ragione che aquista un rè potente heretico sopra un regno cattolico». Archivio di Stato di Roma [en adelante, ASR], Famiglia Odescalchi, 2-M-1, n. 17. Parecer del cardenal Benedetto Odescalchi. Di casa, 27 de septiembre de 1661 .

25. El texto íntegro de la Declaración de Breda, firmada el 4 de abril de 1660, se encuentra recogido en Kenyon, J. P. (ed.): The Stuart Constitution, 1603-1688. Documents and Commentary. Cambridge, 19862, pp. 331-332. En relación con la significatividad confesional en el negociado político en la segunda mitad del Seiscientos, vid. Thompson, A. C.: «After Westphalia: Remodeling a Religious Foreign Policy», en Onnekink, D. (ed.): War and Religion after Westphalia, 1648-1713. Farnham, 2009, pp. 47-67.

26. Samuel Pepys alude en otra de las páginas de su diario cómo el domingo 21 de septiembre de 1662 acudió a misa a Saint James, mezclado entre la muchedumbre que seguía la carroza de la reina. En su relato destacó la decoración del altar, la devoción de doña Catalina y cómo el sermón se pronunció en portugués. PEPYs, op. cit., p. 143. Sobre la praxis devocional regia y el carácter político del oratorio, vid. PinTo, A. C.: «The processional Cross of the Chapel

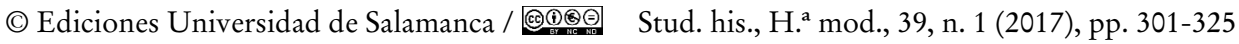


entre lusitanos e ingleses se presentaban como elementos de atracción, a la par que despertaban suspicacias entre la comunidad reformada ${ }^{27}$.

En el palacio de Somerset House, residencia la reina madre Enriqueta María desde el desembarco de su nuera, también estaban toleradas las liturgias católicas, pues en sus capitulaciones se había incluido tal cláusula ${ }^{28}$. Frente a la creciente notoriedad de ambas capillas regias, la legislación protestante procuró frenar su avance, regulando la naturaleza de la feligresía y los capellanes, así como la lengua de la predicación. Sin embargo, su acatamiento fue muy laxo a tenor de su reiteración a lo largo de dicho reinado ${ }^{29}$. Merced al amparo de los acuerdos regios y la apertura de oratorios en las casas de los inmunes ministros europeos, los altares fabricados en la City actuaron como centros de poder católicos destinados a la conservación y práctica del culto romano, aunque se vieran influidos por las coyunturas políticas.

En este panorama de tolerancia práctica, Francisco de Melo adaptó el convento de Saint James para la residencia de su embajada y se arrogó la capilla de los padres

of Catherine of Braganza», The Burlington Magazine, XCIX: 648, 1997, pp. 76-78; y CorP, E.: «Catherine of Braganza and Cultural Politics», en CAmpbell OrR, C. (ed.): Queenship in Britain, 1660-1837. Royal Patronage, Court culture and Dynastic Politics. Manchester, 2002, pp. 53-73.

27. Uno de los aspectos más destacados de la capilla de la reina Catalina fue la música. En distintas partes de su diario, Samuel Pepys destacaría el interés que le despertaba escuchar aquellas melodías. El gusto por la música italiana en el oratorio regio ha sido estudiado en LEECH, P.: «Musicians in the Catholic Chapel of Catherine of Braganza, 1662-1692», Early Music, 29: 4, 2001, pp. 570-587. La nómina de capellanes de la Queen’s Chapel se encuentra en RAU, «D. Catarina...», op. cit., p. 325 y WeALE, op. cit., pp. xxxi y 173-174.

28. La capilla de Somerset House se comenzó a edificar en septiembre de 1632. Diseñada por Inigo Jones, el arquitecto de la Queen's Chapel, se dedicó a la Virgen María. Newman, J.: «Inigo Jones and the Politics of Architecture», en Sharpe, K. y LAKe, P. (eds.): Culture and politics in Early Stuart England. Stanford, 1993, pp. 229-255. Con permiso de Carlos I, el motivo de su fabricación fue la acogida de de los religiosos capuchinos franceses que llegaron para ponerse al servicio de la reina Enriqueta María. Las obras duraron cuatro años, abriéndose el día de 8 de diciembre de 1636, festividad de la Inmaculada Concepción de María. Wainwright, J. P.: «Sounds of piety and devotion: Music in the Queen's Chapel», en GrIfFey, E. (ed.): Henrietta Maria. Piety, Politics and Patronage. Aldershot, 2008, pp. 198-199.

29. Las distintas resoluciones adoptadas por Carlos II respecto a los usos, prácticas y gobierno de las capillas de las reinas y los embajadores de príncipes europeos, se encuentran en The National Archives, Public Record Office [en adelante, TNA, PRO], State Papers 29/57, fols. 250rv. Proclama de Carlos II. Whitehall, s. f., julio de 1662; TNA, PRO, State Papers 29/261, f. 173. Proclama de Carlos II. Whitehall, 11 de septiembre de 1667. Londres: John Bill y Christopher Barker, 1667; At the Court at Whitehall, the Third of October, 1676, Londres: John Bill y Christopher Barker, 1676; y TNA, PRO, State Papers 29/386, f. 175r. Warrant del Privy Council. Whitehall, 27 de octubre de 1676.

(C) Ediciones Universidad de Salamanca / ®@ Stud. his., H. ${ }^{a}$ mod., 39, n. 1 (2017), pp. 301-325 
seráficos ${ }^{30}$. A comienzos de 1673, John Evelyn registró en su diario cómo el legado luso le mostró su curiosa colección de libros y pinturas durante una visita a su casa. Sin aportar mayores detalles acerca del contenido de la biblioteca, se desprende de dicha anotación cómo el portugués no dejó de cultivar su afición poética y su faceta artística Inglaterra. Ambas cualidades, además de su bagaje cultural, serían elogiadas por dicho erudito al describirle como «a person of good parts, and a virtuous man ${ }^{31}$.

Las negociaciones políticas de Melo en la corte británica y su representación diplomática afianzaron los lazos creados con doña Catalina. Quien ejerciera el servicio palatino cuando ella aún era infanta, además de haber ostentado el puesto de su camarero mayor en los primeros meses de reinado como consorte, se estaba convirtiendo en una pieza fundamental para los intereses lusitanos con la corona Estuardo. Con la muerte del conde de Clarendon en 1674, el entonces lord chamberlain de la reina, Henry Hyde, heredó el título de su padre. La dedicación a los negocios familiares motivó su renuncia al oficio en la casa real. La vacante de uno de los cargos más honorables en la estructura doméstica de la monarquía inglesa, y uno de los más próximos a la figura de la reina portuguesa, se presentó a esta como una ocasión propicia para reconocer a su compatriota con un puesto de su total confianza. Después de algunos meses, la autoridad de la Braganza y su voluntad graciosa cristalizaron con la designación de Melo como su chambelán en el verano de $1675^{32}$.

El nombramiento de un extranjero para tan alta distinción contó con el asenso del soberano. Carlos II, en un intento por complacer a su esposa, hubo de enfrentarse a las reticencias disimuladas de ciertos sectores de la gentry católica que se consideraban más meritorios de la munificencia regia. En este punto, la condición dual que confluía en la persona de dom Francisco suscitó el debate en la corte sobre si conservaría la representación política del monarca portugués, compatibilizando las funciones diplomática y doméstica al mismo tiempo; o, por el contrario, renunciaría a sus credenciales para servir en exclusividad a la reina de

30. El uso cortesano y profano dado a las habitaciones que componían el convento y, más concretamente, al espacio de culto, fue una de las principales preocupaciones de los religiosos franciscanos tras conocerse su traslado al palacio de Somerset House. Espelho de penitentes e Chronica de Santa Maria de Arabida. Lisboa, 1737, p. 387.

31. Evelyn, J.: Memoirs (edición de W. Bray). Londres, $1819^{2}$, vol. 1, p. 459. Como subraya Susana Varela Flor, la ausencia de un inventario de bienes que hubiera podido acompañar su último testamento, fechado en 1678, impide conocer el alcance de su patrimonio cultural y artístico. VAREla Flor, op. cit., p. 364.

32. El nombramiento tuvo lugar en Windsor, el 16 de agosto de 1675. Calendar of State Papers. Domestic, Charles II. Londres, 1907, vol. 17, p. 263.

(C) Ediciones Universidad de Salamanca / ®@ Stud. his., H. ${ }^{a}$ mod., 39, n. 1 (2017), pp. 301-325 
Inglaterra. Como observase Paolo Sarotti, residente veneciano en Londres, todo apuntaba a que el regente Pedro de Braganza también contentaría a su hermana y no mostraría reparos a su deseo de rodearse de dependientes afines. El carácter de embajador presentaba una serie de obligaciones para con su señor natural, inherentes en el oficio y las propias instrucciones, dirigidas al favorecimiento de los intereses particulares lusitanos que no conciliaban con las implicaciones que significaba pasar a ser familiar de la reina Catalina y desempeñar un cargo discrecional en la casa real británica. No obstante tales distinciones teóricas, en un período de buena correspondencia entre ambas coronas, dom Pedro le mantuvo como su legado en la corte londinense ${ }^{33}$.

\section{El pleito tipográfico del embajador Chamberlain Melo}

Sin haberse cumplido un año de su designación como lord chamberlain, el diplomático se vio inmerso en una acalorada querella pública acerca de su autoridad y los límites de sus atribuciones. La problemática surgió por la imprudencia de Melo para patrocinar y avalar con la estampa de su sello la publicación de un libro católico: The Great Sacrifice of the New Law. Esta obra teológica bilingüe, escrita en latín y acompañada de la correspondiente traducción de las epístolas en vernácula inglesa, salió de la pluma del sacerdote James Dymock, quien tenía asiento en el banco de capellanes de la embajada portuguesa desde hacía poco tiempo ${ }^{34}$. El objetivo del autor, declarado por él mismo en el prefacio, era difundir los misterios de la misa y renovar la espiritualidad católica, facilitando el acceso de la liturgia a los fieles londinenses en su propia lengua ${ }^{35}$. Atento a su «señor»y su piedad, dedicó el tratado a dom Francisco, señalando directamente su persona

33. Carta de Paolo Sarotti a Nicolò Sagredo, dogo de la república de Venecia. Londres, 16 de agosto de 1675. Calendar of State Papers and Manuscripts Relating to English Affairs Existing in the Archives and Collection of Venice, and in other Libraries of Northern Italy. Londres, 1947, vol. 38, p. 443.

34. Este sacerdote católico, oriundo de Scrivelsby, en Lincolnshire, se formó en el continente, posiblemente en el colegio de los ingleses de Lisboa y, posteriormente, se ordenaría en el seminario inglés de París. Desde la capital francesa regresó a Inglaterra hacia 1660 como misionero. Durante unos años, ejerció de capellán del duque de Norfolk, a quien dedicaría su obra Le vice ridicule et la vertu loüée (Lovaina, 1671). The Dublin Review, 108, 1891, p. 200; y Callow, J.: «James Dymock», Dictionary of National Biography, versión on-line: http:// www.oxforddnb.com/index/8/101008362/ (Consultado el 10/12/2015).

35. Pecklers, K. y Ostdiek, G.: «The History of Vernaculars and Role of Translation», en Foley, E., Baldovin, J. F. y Collins, M. (eds.): A Commentary on the Order of Mass of Roman Missal. Collegeville, 2011, p. 47.

(C) Ediciones Universidad de Salamanca / ®@ Stud. his., H. ${ }^{a}$ mod., 39, n. 1 (2017), pp. 301-325 
como mecenas de este Popish Book ${ }^{36}$. El reconocimiento hacia el cuidado y coste con que este mantenía «that Sacred Place where this Divine Mystery is daily celebrated» no solo venía motivado por el servicio religioso que unía al capellán con su patrocinador ${ }^{37}$. Su estrecha relación con los ministros bragancistas había nacido del débito hacia la protección que recibió en distintas circunstancias adversas para su persona y la utilización de la inmunidad diplomática de la casa para la clandestina circulación de correspondencia y libros católicos. Asimismo, la inclusión de un presbítero oficiando la liturgia, durante la consagración del vino, ante un crucifijo y con un misal abierto tampoco parece arbitraria (Fig. 2). Además de ilustrar el momento de la transustanciación de Jesucristo, materia sobre la que realizó una sólida defensa teórica en dicha obra, el grabado podría interpretarse como una representación simbólica de las misas que se celebraban en el oratorio luso, en las que participaría el propio padre James ${ }^{38}$.

Pensada como una edición inicial de un centenar de ejemplares, concretada para el consumo privado y particular de los domésticos de la reina, la obra se multiplicó como los inconvenientes para el embajador. No era la primera ocasión en que la casa de la reina Catalina era provista de libros, impresos y otros ornamentos y elementos romanos exportados desde el continente. En 1662, poco después de su llegada a la corte londinense, uno de sus predicadores le envió un cargamento de cuarenta y siete obras para su uso personal y el de sus criados. Entre la relación hecha en la Custome House, destacaron unos tratados de filosofía natural, las disputas teológicas del carmelita descalzo fray Felipe de la Santísima Trinidad, el capuchino fray Éloi de la Bassée y sus Flores totius theologice practise, textos litúrgicos romanos, el Epitome Rubricarum Breviarij Romani y veinte volúmenes de Thomas a Kempis ${ }^{39}$. Procedente de Francia, una nueva remesa se recibió a comienzos del año siguiente, con varias pinturas, tarjetas y crucifijos, incluyendo las cajas distintos escritos de referencia en materia religiosa reservados para la Queen's Chapel y sus capellanes que comenzaban a dotarse de estos otros recursos bibliográficos. La partida fue mucho más modesta que la precedente, aunque mantuvo semejantes pretensiones espirituales. Aparte de incluir dos Biblias y

36. En 1668, Francisco de Melo Manuel también había sido el destinatario de una obra médica, Stadium apollinare sive Progymnasmata medica, ad monspeliensis apollinis, de Fernão Mendes. En la dedicatoria, este hispano-portugués exaltó las virtudes y prendas del ministro como caballero y comendador de la Ordem de Cristo portuguesa. Mendes, F.: Stadium apollinare sive Progymnasmata medica, ad monspeliensis apollinis. Lyon, 1668.

37. Dyмоск, J.: The Great Sacrifice of the New Law. Londres, 1676, s. p.

38. Callow, op. cit.

39. TNA, PRO, State Papers 29/367, f. 91. Relación de obras enviadas desde Flandes por un predicador de la reina. S. l., 20 de noviembre de 1662.

(C) Ediciones Universidad de Salamanca / ®@ Stud. his., H. ${ }^{a}$ mod., 39, n. 1 (2017), pp. 301-325 
un Nuevo Testamento, también comprendió desde la hagiográfica Vida de la madre Teresa del jesuita Francisco de Ribera hasta el Libro del reino de Dios y del camino por do se alcanza, trasunto manual de sacerdotes de su compañero en el instituto ignaciano Pedro Sánchez, pasando por el Hortum pastorum del doctor en teología Jacques Marchant y el Promptuarium catholicum del irlandés Thomas Stapleton ${ }^{40}$.

Sendas cargas, representativas en cantidad y relevantes cualitativamente, ponen de manifiesto el interés de la reina Catalina por cultivar entre los miembros de su casa la religiosidad católica que ella misma profesaba. La heterogeneidad y riqueza del saber teológico contenido en tales volúmenes se debía difundir entre los muros del palacio y la capilla regia a través de las lecturas, silentes y personales, y las homilías de los capellanes. Esta dinámica de conservación religiosa e incentivación confesional mediante la palabra escrita puede considerarse una forma discreta de proselitismo indirecto hacia aquellos protestantes dependientes de su familia. Con tales premisas, dada su formación y conociendo estrechamente la aplicación devocional de la reina, el chamberlain portugués se insertó dentro de esta lógica de alimentar el alma de los servidores palatinos con golosinas impresas, pues esta era una de sus múltiples atribuciones dentro de la casa real ${ }^{41}$.

El carácter edificante de la obra, el objetivo pragmático y el contenido pedagógico de la misma determinaban su idoneidad para difundirla entre los domésticos de la Braganza. El conocido tipógrafo londinense Anthony Lawrence ejecutó el encargo según las indicaciones que había recibido, aunque en el pie de imprenta omitió cualquier mención a su autoría por tratarse, al menos en teoría, de una publicación privada para consumo particular o, en cambio, permanecer en el anonimato y guardarse de cualquier dependencia derivada de su trabajo. Al parecer, sin mediar orden o advertencia previa por mano del signatario portugués, el impresor se habría tomado la licencia de aumentar la tirada, «haciendo de

40. TNA, PRO, State Papers 29/67, f. 133r. Relación de las cosas que contenían las caja destinadas a la Queen's chapel, firmada por Ludovic [Louis] Stuart d'Aubigny, capellán mayor de Catalina de Braganza. S. 1., 16 de enero de 1662. Estos libros estaban en posesión de Francis Cook, habiendo dado el monarca orden a los Farmers of Customs de Londres para que se los entregasen. En junio de 1672, otro de los capellanes portugueses de la reina recibió un libro, junto con una caja para Catalina de Braganza, importado en un barco de Rouen. Calendar of Treasury Books. Londres, 1908, vol. 3, p. 1251.

41. En relación a la producción de textos devocionales y teológicos con fines catequéticos, vid. BouzA, F.: «Público pastoral: de la prédica a la imprenta. Da golosina y otras industrias de misionalización», en Idem: Papeles y opinión. Políticas de publicación en el Siglo de Oro. Madrid, 2008, pp. 45-65. Para el caso inglés, vid. Walsham, A.: «"Domme preachers”? Postreformation English Catholicism and the culture of print», PastEPresent, 168, 2000, pp. 72-123.

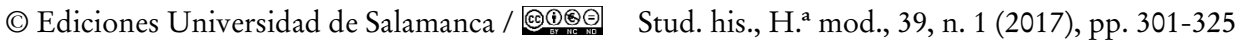


noventa, novecientos» ${ }^{42}$. El desproporcionado volumen de ejemplares aparecidos de la explicación de la misa superó los originales umbrales de previsión y derivó en la propagación por la ciudad de Londres. La divulgación fue tal que, al trascender los muros del palacio y la capilla regia, uno de aquellos llegó «al obispo de esta corte», el mencionado prelado anglicano Henry Compton ${ }^{43}$. Esta circulación espontánea dentro del ámbito jurisdiccional reformado y su postura abiertamente opuesta a la profusión de literatura católica acabarían por causar un lance mediatizado por el clima de creciente confrontación religiosa que se estaba viviendo en Londres ${ }^{44}$. De manera casi inmediata, el mitrado notificó el exceso de Melo a Carlos II y alertó al Privy Council de la publicación de un Popish book. El revuelo que despertó en Whitehall la queja del obispo contra tal osadía provocó el inicio de un procedimiento judicial, dada la gravedad de la materia y la turbación generada entre los ministros ingleses por provenir el patrocinio y anuencia de un libro «prohibido» del camarero mayor de la reina.

En un primer momento, las pesquisas se dirigieron hacia Lawrence, de cuyas prensas había salido el controvertido libro. Las sospechas de Compton fundadas, según su propio criterio, sobre su regular actividad editorial al servicio de los católicos llevaron a ponerle bajo la custodia de un messenger enviado por el consejo y a registrar el local de Exeter Street donde desarrollaba su trabajo librero habitualmente. Como responsable último del «unlawfull work», las autoridades le obligaron a entregar al warder de la Company of Stationers el texto original y todas las copias que hubiesen salido de sus tipos ${ }^{45}$. Además de incautarle la producción, le restringieron su actividad con la prohibición, so pena de mayor castigo, de reeditar The Great Sacrifice o componer cualquier otro de temática papista ${ }^{46}$.

El impresor no actuó motu proprio, a tenor de los informes obtenidos durante las averiguaciones. En la sesión del Privy Council del 4 de agosto se encausó a James Thompson, un sombrerero católico afincado en Eagle Court, cerca del

42. AGS, Estado, leg. 2553. Carta de Bernardo de Salinas a Pedro Coloma. Londres, 3 de agosto de 1676.

43. Sobre la relevancia política de este obispo que administró la diócesis de Londres durante el reinado de los últimos Estuardo, vid. Coleby, A. M.: «Henry Compton», Dictionary of National Biography, version on-line: http://www.oxforddnb.com/index/101006032 [Consultado el 12/01/2016].

44. La realidad confesional católica en la década de 1670 , con posterioridad a la revocación de la Liberty of conscience, se expone en Miller, J.: Popery E Politics in England, 1660-1688. Cambridge, 2008, pp. 121-153.

45. Carpenter, E.: The Protestant Bishop: Being the Life of Henry Compton, 1632-1713, Bishop of London. Longmans, 1956, p. 67.

46. TNA, PRO, State Papers 29/383, fol. 241r. Orden del consejo para que un mensajero custodiase a Anthony Lawrence, impresor. Whitehall, 21 de julio de 1676.

(C) Ediciones Universidad de Salamanca / ®@ Stud. his., H. ${ }^{a}$ mod., 39, n. 1 (2017), pp. 301-325 


\section{CRISTINA BRAVO LOZANO \\ DIPLOMACIA, SERVICIO CORTESANO Y TINTAS CATÓLICAS: \\ LA QUERELLA LONDINENSE DE FRANCISCO DE MELO MANUEL}

palacio real de Somerset House donde residía y tenía su capilla la reina Catalina. Expidiéndosele la correspondiente orden de vigilancia hasta su presentación ante el consejo, se le acusaba de intento de soborno al tipógrafo para que fuera diligente $\mathrm{y}$ «take upon him the sole printing and publishing of a Popish book entitled The Great Sacrifice of the New Law» ${ }^{47}$. El mismo día también se decretaron otros dos warrants, uno para Antoine de Marville, secretario del embajador luso, considerado artífice de la autorización que finalmente signó el embajador o, en su defecto, promotor de la mudanza de las cifras de la tirada; y, el otro, para el autor intelectual de la obra, el capellán James Dymock ${ }^{48}$.

Esta querella tuvo una honda repercusión política, aunque sin llegar a constituir un asunto de Estado, ni derivar en un conflicto diplomático entre Inglaterra y su aliado portugués. La suerte de los implicados en la impresión difirió según los casos. El impresor Lawrence no fue enjuiciado por disposición regia, al manifestar su arrepentimiento por el delito imputado. Sus revelaciones permitieron, en gran medida, hallar a otros autores y libros católicos sin licencia ${ }^{49}$. Por su parte, el plumista Marville apeló a la indulgencia del monarca Estuardo y salió bajo fianza de la prisión de la Gatehouse de Westminster ${ }^{50}$. El mayor perjudicado fue Francisco de Melo Manuel, quien sufrió las consecuencias en su representación y prestigio.

Entre las noticias que anticipó el residente español en Londres, Bernardo de Salinas, se anunciaban algunos desaires y burlas hacia la persona del ministro «con que juzgo se apagará esta llamarada». La tibieza de tales manifestaciones no se correspondió con la resolución regia y las consecuencias derivadas de la causa abierta contra el luso. Con independencia de su inmunidad diplomática y el carácter público de su ministerio, el Privy Council le convocó para declarar por

47. TNA, PRO, State Papers 29/384, fol. 149r. Orden del consejo para que George Gillyat, mensajero, custodiase a James Thompson, sombrerero en Eagle Court. Whitehall, 4 de agosto de 1676. La cursiva del título es nuestra.

48. TNA, PRO, State Papers 29/384, fol. 147r. Orden del consejo para que John Wickham, mensajero, custodiase a Antoine de Marville, secretario de Francisco de Melo Manuel, y otra orden para que hiciese lo propio con el sacerdote James Dymock. Whitehall, 4 de agosto de 1676.

49. Calendar of State Papers. Domestic, Charles II. Londres, 1909, vol. 18, p. 323. Whitehall, 13 de septiembre de 1676.

50. En la sesión del consejo que dirimió la cuestión de la impresión, Antoine de Marville reconoció su error y pidió formalmente el perdón de Carlos II, en atención a los inconvenientes que estaba provocando a las personas que tenía a su cargo. Atento a lo cual, el rey le puso en libertad tras el pago de una fianza, con la condición de acudir a los tribunales siempre que fuera requerido en relación con esta causa. TNA, PRO, State Papers 29/384, fol. 178r. Orden de libertad bajo fianza a favor de Antoine de Marville, secretario de Francisco de Melo Manuel. Whitehall, 9 de agosto de 1676.

(C) Ediciones Universidad de Salamanca / ख@@ Stud. his., H. ${ }^{a}$ mod., 39, n. 1 (2017), pp. 301-325 
la irreverencia de su permisión en calidad de camarero mayor de la reina. Según recoge el capitán Charles Hatton en una de sus cartas, Melo excusó su asistencia por escrito, amparándose en los derechos del ius gentium y argumentando cómo no estaba en disposición de responder al dicasterio sin la pertinente autorización del príncipe regente al que representaba. En su lugar envió a su secretario, también imputado por la misma causa, para que ofreciera su testimonio y clarificase lo sucedido con la impresión. En su exposición, Marville manifestó cómo «he only licensed 100 [books] for the use of the Queen's servants, but a figure of nine was put into the license without his privity, after he had signed it, with made it for 900». Conforme al tenor de esta afirmación, surgen distintos interrogantes que, a falta del proceso judicial completo, resulta complicado dilucidar. ¿ ¿ La orden del ministro portugués efectivamente fue la de imprimir un centenar, aduciéndose la ignorancia de tal acción como un recurso acostumbrado en la retórica exculpatoria, cuando en realidad pudo suscribir o conocer cuál sería la tirada final? ¿Sería esta una forma de disimulación para desobligarse de un imprevisto embarazoso y no empeñarse más en la dependencia a fin de no verse injuriado? ¿Dom Francisco habría sido víctima de una mano interesada que, sin su consentimiento, manipuló la primigenia licencia y alteró el número de ejemplares para multiplicar la edición y perjudicarle en su dignidad pública y / u oficio privado? Entonces, ¿la controversia habría nacido de una intriga palatina para comprometer su persona y apartarlo de la corte, toda vez que se bloqueaba el catolicismo áulico por esta vía? ¿Subyació el pragmatismo de quien modificó la autorización, aprovechando la cobertura legal que ofrecía tal permiso de acuerdo con los privilegios y la condición diplomática y cortesana del signatario? En cualquiera de los casos, Francisco de Melo Manuel no quedaba exento de responsabilidad, pues sus razones se juzgaban simuladas y la mayoría de los londinenses opinaba cómo «he will lose his key» por todo lo sucedido ${ }^{51}$.

El sentir generalizado no distó de la decisión del monarca. Carlos II, valiéndose de su autoridad sobre los oficiales de la casa real, le depuso fulminantemente del puesto de lord chamberlain de la reina. Este cargo discrecional le había sido concedido por la exclusiva munificencia regia ${ }^{52}$. Se desconoce si la reina Catalina

51. Maunde Thompson, E. (ed.): Correspondence of the Family of Hatton being Chiefly Letters Addressed to Christopher First Viscount Hatton. Londres, 1878, vol. 1, pp. 137-138.

52. Aunque la comparecencia del secretario de Melo ante el consejo y el fallo se produjo una semana después, Bernardo de Salinas ya vaticinó el 3 de agosto cuáles iban a ser las consecuencias de esta imprudencia. AGS, Estado, leg. 2553. Carta de Bernardo de Salinas a Pedro Coloma. Londres, 3 de agosto de 1676. No obstante, el residente confirmó la decisión de Carlos II meses después. AGS, Estado, leg. 3955. Carta de Bernardo de Salinas a Carlos II. Londres, 9 de noviembre de 1676.

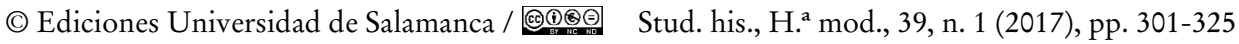


dispuso de margen para interceder en su favor durante el proceso. No obstante, con esta medida la Braganza no solo se veía privada de uno de sus más cercanos servidores y confidentes, sino que se apartaba de su entorno familiar a una influyente figura que se movía con habilidad en los círculos del poder político y el aula regia. En cambio, la revocación de su empleo cortesano fue bien recibida por sectores contrarios al predominio de católicos en la servidumbre de la consorte portuguesa, entre ellos, el lord Treasurer Danby y sus hechuras, que tenían aspiraciones particulares para tal ocupación.

Junto con la licencia como dependiente palatino, también se ordenó el cierre de su capilla «con pretexto de que, aunque es casa que la reina le dio, es terreno de palacio", es decir, jurisdicción bajo potestad regia y no área preservada por las prerrogativas diplomáticas ${ }^{53}$. La resolución de Carlos II trascendió la esfera doméstica para adquirir un cariz político y religioso, pues se anulaba la capacidad de maniobra de este epicentro de mecenazgo y difusión de los valores romanos, toda vez que la comunidad católica perdía uno de sus espacios de culto referenciales en la corte londinense. Sin embargo, la decisión parecía adoptada o, al menos anunciada, desde hacía algunas semanas. En términos similares, y aludiendo a su doble condición, meses atrás de su dependencia impresa se había ordenado la clausura del oratorio, no el abandono de su casa, «por razón de haberle hecho camarero mayor de la reina y, aunque tiene ambos caracteres, alegan que siendo doméstico y posando en palacio, no debe tener capilla» ${ }^{54}$.

La búsqueda de tales justificaciones contra la continuidad del altar luso pone de relieve la eventual oposición hacia estos espacios católicos y el valor conferido a los mismos. La disposición del monarca introdujo novedades respecto a su política de connivencia hacia las capillas diplomáticas erigidas en Londres ${ }^{55}$. Se incrementó la presión sobre los ministros europeos para controlar la naturaleza de sus capellanes y la lengua de la predicación, previniendo el empleo de vasallos de la corona Estuardo y el uso del inglés en la oratoria sagrada por ser unos usos contrarios a la legislación del reino, aparte de los graves inconvenientes de obediencia y reparos en la imagen regia en que podrían derivar. A tenor de las intimidaciones que estaba recibiendo en su oratorio, el español Bernardo de Salinas

53. AGS, Estado, leg. 2552. Carta de Bernardo de Salinas a Carlos II. Londres, 31 de agosto de 1676.

54. Ibidem.

55. Las medidas inglesas respecto al uso y curso regular de las capillas diplomáticas en Londres a finales del Seiscientos, con particular énfasis en la española, se exponen en BRAvo Lozano, C.: Tierras de Misión. La política confesional de la Monarquía de España en las Islas Británicas, 1660-1702. Tesis doctoral inédita. Universidad Autónoma de Madrid. Madrid, 2014.

(C) Ediciones Universidad de Salamanca / ®@ Stud. his., H. ${ }^{a}$ mod., 39, n. 1 (2017), pp. 301-325 
participó a su homólogo en La Haya, Manuel Francisco de Lira, lo que estaba aconteciendo y las medidas adoptadas contra el legado portugués ${ }^{56}$. Los tintes que había tomado la impresión de The great sacrifice llevaron a Lira, sin conocer todavía el fallo del soberano británico, a esta sugestiva reflexión:

bien raro es el lance de Melo, pero quien vive a dos luces, entre embajador y criado, no puede comer a dos carrillos sin riesgo de indignidades, aunque es verdad que son mayores las de no comer a uno, que es lo que sucede a otros que sirven a mejor $\mathrm{amo}^{57}$.

Esta dualidad de servicio, al príncipe regente Pedro de Braganza y a la reina consorte Catalina, implicaba una serie de obligaciones y responsabilidades no siempre fáciles de combinar. Un exceso de autoridad como embajador, una extralimitación en sus funciones domésticas o un ardid palatino en su contra pudieron motivar la disputa en que Francisco de Melo se veía inmerso. Si bien la intención originaria restringía el consumo del tratado al ámbito privado de su «señora», dentro del palacio como espacio inmune para el ejercicio del catolicismo, su puesta en pública circulación discutió la posición del legado y sus designios finales, y provocó su descrédito político. Las connotaciones y diferencias de cada una de las dignidades que ostentaba de manera simultánea, diplomática de un lado y chamberlain, por otro, acabaron por generar un problema de obediencia y un delicado equilibrio de lealtades, aunque fuese a dos miembros de la casa de Braganza ${ }^{58}$. Con su aguda pluma, Lira advirtió esta circunstancia y el carácter tornadizo de la fidelidad. A la

56. En la carta que le envió el secretario de Estado Henry Coventry, se advertía a Salinas el descontento del monarca por determinados abusos y prácticas que daban lugar «al menosprecio y a la inobservancia de las leyes del reino y al escándalo de la religión y del gobierno». Por ello, se le prevenía que los súbditos británicos «no sean de ninguna manera recibidos ni admitidos en vuestra casa y capilla para oír misa o sermón, ni asistir al servicio y ceremonias de la iglesia de Roma y que no sufráis tampoco que ningún sacerdote inglés, escocés o irlandés diga misa o predique en inglés (cosa que nunca antes se practicó por ningún ministro extranjero) ni de que se digan los oficios de ninguna manera». AGS, Estado, leg. 3955. Copia de carta, traducida del francés, de Henry Coventry a Bernardo de Salinas. Londres, 4 de noviembre de 1676.

57. Archives Générales du Royaume de Belgique [en adelante, AGRB], Ambassade d'Espagne à La Hague, 489. Carta de Manuel Francisco de Lira a Bernardo de Salinas. La Haya, 11 de agosto de 1676.

58. En relación con los oficios regios y sus implicaciones, vid. Esteban Estríngana, A. (ed.): Servir al rey en la Monarquía de los Austrias. Medios, fines y logros del servicio al soberano en los siglos XVI y XVII. Madrid, 2012; y Pardo Molero, J. F. y Lomas Cortés, M. (eds.): Oficiales reales. Los ministros de la Monarquía Católica (siglos XVI-XVII). Valencia, 2012. Sobre la vigencia de los conceptos de fidelidad, lealtad y obediencia, vid. VALladares, R.: «Fidelidad, lealtad y obediencia. Tres conceptos en la Monarquía de los Austrias», en Quirós Rosado, R. y Bravo Lozano, C. (eds.): Los hilos de Penélope. Lealtad y fidelidades en la Monarquía de España, 1648-1714. Valencia, 2015, pp. 21-38.

(C) Ediciones Universidad de Salamanca / ®@ Stud. his., H. ${ }^{a}$ mod., 39, n. 1 (2017), pp. 301-325 
par, minusvaloraba con su retórica el papel político del regente lusitano al que el tan cuestionado Melo representaba en Londres. El daño en la dignidad del ministro estaba hecho y solo restaba conocer cuál sería su destino áulico y el de su legación.

No había alcanzado el mes de septiembre de 1676, con los ecos de The great sacrifice y el alcance de su impresión resonando por las calles, cuando el foco de debate en la corte se trasladó de las prensas y el papel a la persona que asumiría el oficio doméstico vacante. La elección adquirió gran relevancia política, pues basculaba entre dos candidatos bien posicionados en los círculos cortesanos: el hijo del gran tesorero Danby y el conde de Sunderland. Con reconocidos valedores en ambos casos, el enviado español escrutó cómo «anda el brazo femenino listo», al apostar por el último la amante del monarca Estuardo, la francesa duquesa de Portsmouth ${ }^{59}$. Sin embargo, de poco sirvieron las instancias que movieron las partes, las intrigas palaciegas y la influencia ejercida en favor de uno u otro postulante. El 18 de noviembre de ese mismo año, la pugna se resolvió con el nombramiento de un tercero, el irlandés Thomas Butler, conde de Ossory e hijo del duque de Ormond ${ }^{60}$.

La destitución formal y el alejamiento del entorno de la reina Catalina no significaron la marcha de Londres de Francisco de Melo Manuel. En un escenario complicado para su cometido, permaneció ejerciendo como embajador del regente Pedro de Braganza, aunque su labor diplomática se desarrollaría en adversas condiciones y desconfianzas políticas, determinadas, en gran medida, por la dependencia impresora y las reticencias de ciertos ministros ingleses para tratar con él por dicha causa. Todo ello no fue óbice para que prosiguiese con su legación y se encargase de gestionar los asuntos lusitanos en la corte británica ${ }^{61}$. Para entonces, y hasta su temprana muerte en 1678, su actitud personal mudó hacia un comportamiento tildado de lisonjero en materia confesional para con Carlos II. En ello hubo de influir el miedo a agravar su ya delicada situación personal y política, o a suscitar una nueva controversia por sus negociados ${ }^{62}$.

59. AGRB, Ambassade d'Espagne à la Hague, 489. Carta de Bernardo de Salinas a Manuel Francisco de Lira. Londres, 21 de agosto de 1676.

60. Morres, H. R., vizconde de Mountmorres: The History of the Principal Transactions of the Irish Parliament. Londres, 1792, vol. 1, pp. 286-287. Para una semblanza de Thomas Butler, vid. Davies, J. D.: «Thomas Butler», Dictionary of National Biography, version on-line: http://www.oxforddnb.com/index/4/101004210/ (Consultado en 12/01/2016).

61. En 1680, y en el contexto del Popish Plot, Francisco de Faria hacía memoria de cómo Melo, entonces ya finado, "was much out of favour with the prince of Portugal» a causa de la promoción de la religión católica. Entre otras razones, ponderaba cómo su discutida caída en desgracia habría venido motivada por el uso de las prensas «before a due time» y la alarma generada por tal producción. The Examination of Francisco de Faria, Delivered at the Bar of the House of Commons. Londres, 1680, p. 2.

62. Muestra de tal disposición se produjo en el ámbito de la capilla de su embajada. Pese a la resolución del monarca para que se procediese al cierre en agosto, el oratorio se mantuvo

(C) Ediciones Universidad de Salamanca / ®@ Stud. his., H. ${ }^{a}$ mod., 39, n. 1 (2017), pp. 301-325 
CRISTINA BRAVO LOZANO

DIPLOMACIA, SERVICIO CORTESANO Y TINTAS CATÓLICAS:

LA QUERELLA LONDINENSE DE FRANCISCO DE MELO MANUEL

\section{Conclusiones}

La impresión de un libro católico en Inglaterra no representaba una novedad a finales del siglo xviI, pese a estar penada por la legislación del reino. La divulgación de este tipo de textos por distintos medios, incluyendo las vías diplomática y palatina, revela cómo estaban destinados a seguir cultivando y conservando la religión romana entre la minoritaria comunidad que permanecía en aquellas islas. Ejemplos como The great sacriface of the New Law ponen de relieve su existencia y profusión, así como la dificultad de las autoridades británicas para su control, dado que veían la luz en la clandestinidad de las prensas locales. La autorización dada por Francisco de Melo Manuel, embajador portugués y camarero mayor de la reina consorte, no hubiera tenido mayor repercusión si la publicación no hubiera trascendido del originario ámbito privado a la circulación pública. Podría haber pasado por otra de tantas obras que se introdujeron disimuladas, fueron difundidas y se requisaron para contrarrestar la influencia y el poder de la palabra escrita en los vasallos de Carlos II Estuardo. La naturaleza de la estampa no fue únicamente la causa principal de la querella, pues subyacieron razones de índole política en consideración de la condición diplomática del anuente y el oficio palatino que fungía.

Este pleito tipográfico, prácticamente desconocido para las historiografías europeas, culminó con el desdoro y el fulminante apartamiento del ministro como lord chamberlain. Los propios contemporáneos, como Bernardo de Salinas, cifraron el infortunio de Melo y el final del negociado, destacable por su rarez $a^{63}$. La salida de don Francisco de Saint James fue la consecuencia política de un avatar que el monarca inglés no pudo disimular, aun cuando existiesen vínculos familiares con el príncipe Braganza ${ }^{64}$. La proyección de esta edición sobre la liturgia romana en

en uso, al menos tres meses más. En noviembre, y conforme a las disposiciones regias, Melo fue advertido por el secretario de Estado, Henry Coventry, para que no permitiese que los católicos ingleses acudiesen a su casa, ni naturales de los reinos británicos oficiasen y predicasen en inglés. Tales amonestaciones particulares también se despacharon con el representante francés marqués de Rouvigny y el residente Bernardo de Salinas. Mientras el español recogió a dichos capellanes en su casa hasta que pasase la borrasca, guardándoles de cualquier exposición pública, sus homólogos galo y portugués acataron las órdenes y licenciaron de sus respectivos oratorios a los sacerdotes vasallos de la corona de Inglaterra. AGS, Estado, leg. 3955. Carta de Bernardo de Salinas a Carlos II. Londres, 9 de noviembre de 1676. Incluye la copia del papel que le envió el secretario de Estado Coventry el 4 de noviembre.

63. Archivo Histórico Nacional [en adelante, AHN], Estado, leg. 147. Carta de Bernardo de Salinas al marqués de Villagarcía. Londres, 24 de agosto de 1676.

64. Biblioteca Nacional de España [en adelante, BNE], Ms. 13372, fol. 49r. Carta de Manuel de Lira al conde de Molina. La Haya, 22 de octubre de 1671.

(C) Ediciones Universidad de Salamanca / ®@ Stud. his., H. ${ }^{a}$ mod., 39, n. 1 (2017), pp. 301-325 
territorio anglicano trascendió la dependencia expuesta. El alcance de tan polémica obra tendría un gran impacto posterior en la corte londinense hasta convertirse en un auténtico best-seller en la época, llegando a distribuirse sin reservas durante el reinado del católico Jacobo II. En once años, el texto expositivo de los principios de la misa católica conocería ocho ediciones, con adendas y correcciones, donde el dedicatario lusitano quedaba como una rémora de la editio princeps original.

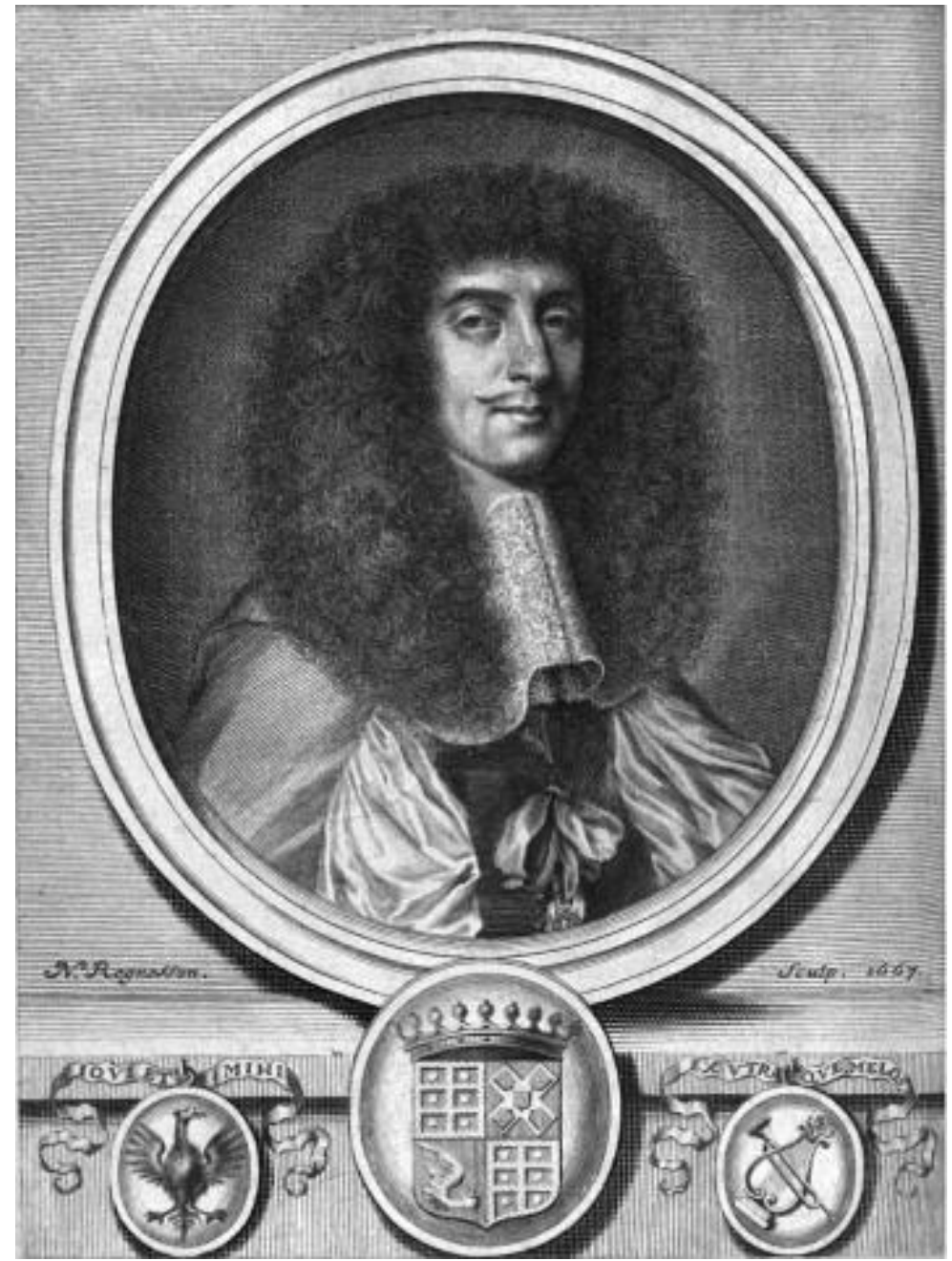

Fig. 1: Francisco de Melo Manuel, grabado para ilustrar la dedicatoria de Mendes, F.: Stadium apollinare sive Progymnasmata medica, ad monspeliensis apollinis. Lyon, 1668.

(C) Ediciones Universidad de Salamanca / ®@ Stud. his., H. ${ }^{a}$ mod., 39, n. 1 (2017), pp. 301-325 

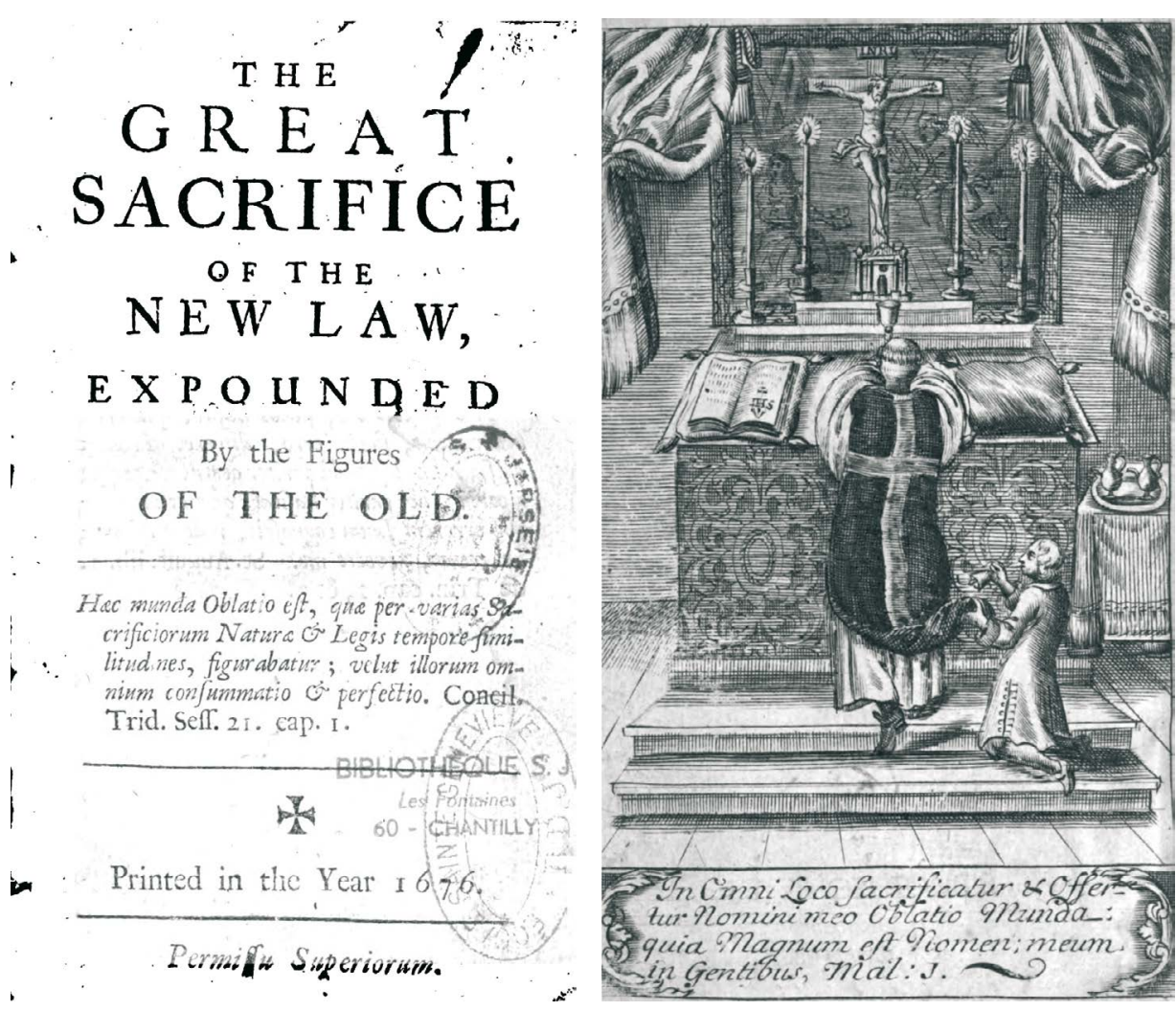

Fig. 2: Portada y grabado de Dyмоск, J.: The Great Sacrifice of the New Law. Londres, s. i., 1676.

4. Bibliografía

Barbosa Machado, D.: Bibliotheca Lusitana. Lisboa, Na Officina de Ignacio Rodrigues, 1747 , tom. II.

Belcher, G. L.: «Spain and the Anglo-Portuguese Alliance of 1661», Journal of British Studies, 15, 1975, pp. 67-88.

Borges de Castro, J. F. (coord.): Collecção dos tratados... Lisboa, Impresa Nacional, 1856, tom. I.

Bouza, F.: «Público pastoral: de la prédica a la imprenta. Da golosina y otras industrias de misionalización», en Idem: Papeles y opinión. Politicas de publicación en el Siglo de Oro. Madrid, CSIC, 2008, pp. 45-65.

Bravo Lozano, C.: Tierras de Misión. La política confesional de la Monarquía de España en las Islas Británicas, 1660-1702. Tesis doctoral inédita. Universidad Autónoma de Madrid. Madrid, 2014.

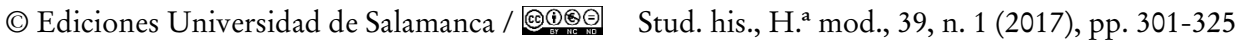


CRISTINA BRAVO LOZANO

DIPLOMACIA, SERVICIO CORTESANO Y TINTAS CATÓLICAS:

LA QUERELLA LONDINENSE DE FRANCISCO DE MELO MANUEL

Calendar of State Papers and Manuscripts Relating to English Affairs Existing in the Archives and Collection of Venice, and in other Libraries of Northern Italy. Londres, Longman, Green, Longman, Roberts, and Green, 1947, vol. 38.

Calendar of State Papers. Domestic, Charles II. Londres, His Majesty's Stationery Office, 1907, vol. 17.

Calendar of State Papers. Domestic, Charles II. Londres, His Majesty's Stationery Office, 1909, vol. 18.

Calendar of Treasury Books. Londres, His Majesty's Stationery Office, 1908, vol. 3, p. 1251.

Callow, J.: «James Dymock», Dictionary of National Biography, version on-line: http:// www.oxforddnb.com/index/8/101008362/ (Consultado en 10/12/2015).

Carpenter, E.: The Protestant Bishop: Being the Life of Henry Compton, 1632-1713, Bishop of London. Londres, Longmans, 1956.

Coleby, A. M.: «Henry Compton», Dictionary of National Biography, version on-line: http://www.oxforddnb.com/index/101006032 (Consultado en 12/01/2016).

Corp, E.: «Catherine of Braganza and cultural politics», en CAmpbell Orr, C. (ed.): Queenship in Britain, 1660-1837. Royal Patronage, Court Culture and Dynastic Politics. Manchester, Manchester University Press, 2002, pp. 53-73.

Davies, J. D.: «Thomas Butler», Dictionary of National Biography, version on-line: http:// www.oxforddnb.com/index/4/101004210/ (Consultado el 12/01/2016).

Dyмоск, J.: The Great Sacrifice of the New Law. Londres, s. i., 1676.

Espelho de penitentes e Chronica de Santa Maria de Arabida. Lisboa, Na Officina de Joseph Antonio da Sylva, 1737.

Esteban Estríngana, A. (ed.): Servir al rey en la Monarquía de los Austrias. Medios, fines y logros del servicio al soberano en los siglos XVI y XVII. Madrid, Sílex, 2012.

Evelyn, J.: Memoirs (edición de W. Bray). Londres, Henry Colburn, 1819², vol. 1.

Grose, C. L.: «The Anglo-Portuguese Marriage of 1662», Hispanic American Historical Review, X, 1930, pp. 313-352.

Herrero Sánchez, M.: «La explotación de las salinas de Punta de Araya. Un factor de conflicto en el proceso de acercamiento hispano-neerlandés (1648-1677)», Cuadernos de Historia Moderna, 14, 1993, pp. 173-196.

Israel, J. I.: Conflicts of Empires. Spain, the Low Countries and the Struggle for World Supremacy, 1585-1713. Londres, The Hambledon Press, 1997.

Kenyon, J. P. (ed.): The Stuart Constitution, 1603-1688. Documents and Commentary. Cambridge, Cambridge University Press, $1986^{2}$.

Leal de Faria, A.: Arquitectos da. A diplomacia portuguesa, 1640-1815. Lisboa, Tribuna, 2008.

Leal de Faria, A.: «Missões Secretas e Negociação. D. Francisco Manoel de Mello e D. Francisco de Mello Manoel ao serviço da Coroa Portuguesa», en Pimentel, M. R. y Monteiro, M. R. (eds.): D. Francisco Manuel de Melo. O Mundo é Comédia. Lisboa, Edições Colibri, 2011, pp. 211-234.

LEECH, P.: «Musicians in the Catholic Chapel of Catherine of Braganza, 1662-1692», Early Music, 29:4, 2001, pp. 570-587.

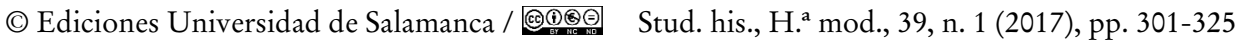


CRISTINA BRAVO LOZANO

DIPLOMACIA, SERVICIO CORTESANO Y TINTAS CATÓLICAS:

LA QUERELLA LONDINENSE DE FRANCISCO DE MELO MANUEL

Madway, L.: «Rites of Deliverance and Disenchantment: The Marriage Celebrations for Charles II and Catherine of Braganza, 1661-1662», The Seventeenth Century, XXVII:1, 2012, pp. 79-103.

Maunde Thompson, E. (ed.): Correspondence of the Family of Hatton being Chiefly Letters Addressed to Christopher First Viscount Hatton. Londres, Camden Society, 1878, vol. 1.

Mendes, F.: Stadium apollinare sive Progymnasmata medica, ad monspeliensis apollinis. Lyon, Daniel Gayet, 1668.

Miller, J.: Popery E Politics in England, 1660-1688. Cambridge, Cambridge University Press, 2008, pp. 121-153.

Morres, H. R., vizconde de Mountmorres: The History of the Principal Transactions of the Irish Parliament. Londres, 1792, T. Cadell, vol. 1.

Newman, J.: «Inigo Jones and the Politics of Architecture», en Sharpe, K. y Lake, P. (eds.): Culture and politics in Early Stuart England. Stanford, Stanford University Press, 1993, pp. 229-255.

Pardo Molero, J. F. y Lomas Cortés, M. (eds.): Oficiales reales. Los ministros de la Monarquía Católica (siglos XVI-XVII). Valencia, Universidad de Valencia, 2012.

Pecklers, K. y Ostdiek, G.: «The History of Vernaculars and Role of Translation», en Foley, E., Baldovin, J. F. y Collins, M. (eds.): A Commentary on the Order of Mass of Roman Missal. Collegeville, Liturgical Press, 2011, pp. 35-72.

Pepys, S.: Diarios. Sevilla, Renacimiento, 2014.

Pincus, S.: 1688, la primera revolución moderna. Barcelona, Acantilado, 2013.

Pinto, A. C.: «The processional Cross of the Chapel of Catherine of Braganza», The Burlington Magazine, XCIX: 648, 1997, pp. 76-78.

Prestage, E.: D. Francisco Manuel de Mello. Esboço Biographico. Coimbra, Imprensa da Universidade, 1914.

RaU, V.: «D. Catarina de Bragança - Raínha de Inglaterra», O Instituto. Revista científica e literaria, 98, 1941, pp. 5-330.

Rau, V.: Estudos sobre a História do Sal Português. Lisboa, Editorial Presença, 1984.

Santos Pérez, J. M. y Cabral de Souza, G. F. (eds.): El desafío holandés al dominio ibérico en Brasil en el siglo XVII. Salamanca, Ediciones Universidad de Salamanca, 2006.

The Dublin Review, 108, 1891.

The Examination of Francisco de Faria, Delivered at the Bar of the House of Commons. Londres, s. i., 1680.

Thompson, A. C.: «After Westphalia: Remodelling a Religious Foreign Policy», en OnneKink, D. (ed.): War and Religion after Westphalia, 1648-1713. Farnham, Ashgate, 2009, pp. 47-67.

Thurley, S.: «The Stuart Kings, Oliver Cromwell and the Chapel Royal 1618-1685», Architectural History, 45, 2002, pp. 238-274.

Valladares, R.: «Fidelidad, lealtad y obediencia. Tres conceptos en la Monarquía de los Austrias», en Quirós Rosado, R. y Bravo Lozano, C. (eds.): Los hilos de Penélope. Lealtad y fidelidades en la Monarquía de España, 1648-1714. Valencia, Albatros Ediciones, 2015, pp. 21-38.

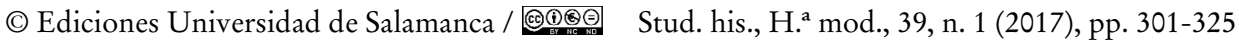


CRISTINA BRAVO LOZANO

DIPLOMACIA, SERVICIO CORTESANO Y TINTAS CATÓLICAS:

LA QUERELLA LONDINENSE DE FRANCISCO DE MELO MANUEL

Valladares, R.: La rebelión de Portugal, 1640-1680. Guerra, conflicto y poderes en la monarquía hispánica. Valladolid, Junta de Castilla y León, 1998.

Varela Flor, S.: «D. Francisco de Melo Manuel da Câmara (1626-1678): biografia, património, estatuto social e fidelidades», Análise Social, 215:1:2, 2015, pp. 356-381.

Vieira, A.: Obras escolbidas. Prefacios e notas de António Sérgio e Hernâni Cidade. Lisboa, Sá da Costa, 1951, vol. II.

Wainwright, J. P.: «Sounds of Piety and Devotion: Music in the Queen's Chapel», en Griffey, E. (ed.): Henrietta Maria. Piety, Politics and Patronage. Aldershot, 2008, pp. 195-214.

Walsham, A.: “"Domme preachers"? Post-reformation English Catholicism and the culture of print», PastEPresent, 168, 2000, pp. 72-123.

Weale, J. C. M. (ed.): Registers of the Catholic Chapels Royal and of the Portuguese Embassy Chapel, 1662-1829. Londres, J. Whitehead \& Son, 1941, vol. 38.

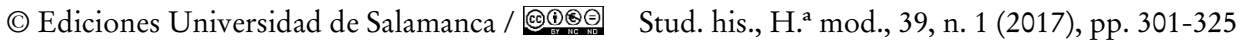


